\title{
El pasado reciente en la escuela. Relatos de estudiantes universitarios ${ }^{1}$
}

Recent Past in School. Stories of College Students O passado recente na escola. Relatos de estudantes universitários

Diego H. Arias-Gómez²

\section{Resumen}

El presente artículo expone algunos hallazgos de una investigación cuyo propósito consistió en ahondar en las ideas de estudiantes de licenciatura sobre el pasado reciente de su país. Así, se profundiza en el tema de la enseñanza de la historia reciente en relación con la percepción que tienen estudiantes universitarios de licenciatura sobre el pasado próximo de su nación. El escrito expone, inicialmente, algunos elementos teóricos sobre historia reciente, la memoria y su enseñanza; posteriormente se detalla el horizonte cualitativo de la estrategia metodológica y la población con la cual se trabajó; finalmente se muestran algunos resultados de la investigación que especialmente postulan la importancia de la violencia como núcleo explicativo de la historia reciente; como cierre se hace una discusión de los resultados.

\section{Palabras clave}

enseñanza del pasado reciente; enseñanza de la historia reciente; enseñanza de la historia; pedagogía de la memoria; escuela

\section{Abstract}

This paper presents some of the findings of a research that aimed to delve into the ideas of undergraduate students about the recent past of their country. Thus, we delve into the subject of teaching recent history in relation to the perception that undergraduate university students have about the near past of their nation. The text initially presents some theoretical elements about recent history, memory and teaching it; it then describes in detail the qualitative horizon of the methodological strategy and the target population; finally, the article shows some results of the investigation that particularly postulate the importance of violence as an explanatory nucleus of recent history; finally, the paper concludes with a discussion of the results.

\section{Keywords}

teaching recent past; teaching recent history; teaching history; pedagogy of memory; school

\section{Resumo}

0 presente artigo expõe algumas descobertas de uma pesquisa cujo propósito foi aprofundar nas ideias de estudantes de licenciatura sobre o passado recente do seu país. Assim, aprofunda-se no tema do ensino da história recente em relação com a percepção dos estudantes universitários de licenciatura sobre o passado próximo da sua nação. 0 texto apresenta, inicialmente, alguns elementos teóricos sobre a história recente, a memória e seu ensino; posteriormente, estabelece-se o horizonte qualitativo da estratégia metodológica e a população da pesquisa. Finalmente, apresentam-se alguns resultados da pesquisa que postulam o papel da violência como núcleo explicativo da história recente; para finalizar é realizada uma discussão dos resultados.

\section{Palavras chave}

ensino do passado recente; ensino da história recente; ensino da história; pedagogia da memória; escola

Artículo recibido el 8 de septiembre de 2016 y aprobado el 28 de julio de 2017

1 Artículo con apartes de la investigación “Identificación con la nación propia en jóvenes, maestros en formación. Imaginarios sociales de nación y escuela". Tesis realizada para obtener el título de doctor en Educación del Doctorado Interinstitucional en Educación, sede Universidad Pedagógica Nacional, dirigida por Alexander Ruiz. Algunas partes de este texto fueron socializados en el xii Congreso Iberoamericano de Historia de la Educación Latinoamericana, Cihela, Colombia, 2016.

2 Doctor en Educación, profesor titular del Doctorado Interinstitucional en Educación, Facultad de Ciencias y Educación, Universidad Distrital Francisco José de Caldas, Bogotá, Colombia, diegoarias8@gmail.com 


\section{Introducción}

Un tema clave para la escuela y la educación del continente y del país, en especial para el terreno de las ciencias sociales escolares, lo constituyen la violencia política y los conflictos sociales y armados recientemente acaecidos, por cuanto dicha incursión coincide con los debates sobre la pertinencia y orientación del retorno de la enseñanza de la historia como disciplina, lo mismo que la trascendencia de introducir o no al aula ciertos contenidos considerados neurálgicos para algunos sectores sociales. Las actuales reformas educativas sobre la formación docente (Resolución 02041 de 2016 del Ministerio de Educación Nacional), así como la promulgación de nuevas reglamentaciones curriculares sobre lo que se debe enseñar en la educación básica y media (Derechos Básicos de Aprendizaje) para el caso específico del área de ciencias sociales en Colombia, no solo se han reglamentado de espaldas a la comunidad docente, sino que han eludido la discusión sobre la actual coyuntura histórica que atraviesa el país, en el que décadas de guerra y luchas por la memoria debieran interpelar lo que se enseña en la escuela.

La actual coyuntura en Colombia, marcada por el proceso de desmovilización de una de sus más antiguas guerrillas, vuelve pertinente la reflexión sobre la dinámica histórica de las últimas décadas, especialmente aquellas atravesadas por la guerra y la violencia política, no solo por cuanto se invocan múltiples y variadas causas de este conflicto (Comisión Histórica del Conflicto y sus Víctimas, 2015), sino porque la transición de los grupos armados a la sociedad civil trae aparejada versiones encontradas respecto de los hechos, los protagonistas y las consecuencias de tantos años de confrontación. En este marco, habrá que prestar atención a los debates sobre las versiones de este pasado y a las posibilidades que se presentan en un país que acalla los fusiles de un sector armado importante, cuyos actores exploran otras alternativas políticas para ganarse a la población. Para los interesados en el campo educativo también es clave el análisis del abordaje del pasado cercano en la escuela, ya que más allá del peso que esta institución tenga en la configuración de representaciones de los escolares sobre su nación, es claro que el currículo materializa los debates existentes por establecer las versiones legítimas del conocimiento social (Goodson, 1991).

A tono con el anterior planteamiento, el presente escrito expone algunos hallazgos de una investigación cuyo objetivo fue profundizar en las ideas de estudiantes de licenciatura sobre el pasado reciente de su país. El escrito está organizado de manera que inicialmente se delinean algunos elementos teóricos y metodológicos, posteriormente se exhiben los principales resultados de la investigación y, para finalizar, se presenta una discusión de estos. Cabe anticipar que la violencia y sus secuelas, como marca de lo que han sido las últimas décadas, fueron el aspecto recurrente reportado por los estudiantes que participaron en este estudio.

\section{El pasado reciente en la escuela}

En América Latina la experiencia de las dictaduras en el Cono Sur vitalizó y difundió la necesidad de plantear una lucha por la construcción de significados desde la escuela (Funes, 2006; Higuera, 2012; Rubio, 2013). Aquí la enseñanza de la historia asumió el estudio del pasado reciente como una lucha política por cuestionar verdades oficiales y visibilizar versiones subalternas por algún tiempo desconocidas. Además, el estudio de la historia reciente buscó propiciar en las nuevas generaciones posicionamientos éticopolíticos frente a conflictos pretéritos y presentes de grupos y fuerzas alternativas que chocaron contra el poder hegemónico, es decir, la enseñanza del pasado reciente se utilizó como clave estratégica de formación política escolar (Kriger, 2011).

Aunque tal incorporación al currículo de la historia reciente no estuvo exenta de problemas e incongruencias (De Amézola, 2008), tales como la falta de rigor disciplinar o la manipulación ideológica, su impacto se ha sentido en muchos países del continente golpeados fuertemente por graves conflictos sociopolíticos de larga duración y de trascendencia nacional e internacional. Desde finales del siglo pasado la escuela y la enseñanza de lo social son interpelados por los fenómenos de la historia reciente dentro y fuera de los programas escolares oficiales. 
La intromisión incómoda del pasado cercano en la escuela dramatiza con fuerza el carácter no neutral que siempre han tenido los contenidos de la enseñanza de lo histórico-social (Arias, 2005), y que ahora, a propósito de hechos sensibles y dolorosos para la sociedad, se invoca para que tales acontecimientos nunca se repitan. Para Levín (2007) no es suficiente repudiar, repetir fórmulas de conjuro contra un pasado ominoso (Nunca más, ¡Basta ya!), más bien,

... el desafío es acompañar a los estudiantes en la construcción de una perspectiva crítica que les permita comprender por qué sucedió lo que pasó, comprender qué rasgos, qué características [...] posibilitaron que ocurriera lo que ocurrió y comprender, asimismo, por qué ese pasado ha sido recordado de los modos en que ha sido recordado. (p. 177 ).

Según Kriger (2011), la tradicional misión de la escuela que enfrenta lo cognitivo y lo identitario se tensiona aún más con la enseñanza del pasado reciente y pone en evidencia la importancia del papel de la memoria en las actuales sociedades, especialmente las que dejaron atrás o están tramitando pasados traumáticos. En este sentido, los contenidos $y$ orientaciones de este pasado incorporado en la escuela son polémicos, conflictivos y objeto de disputa por diferentes agencias sociales. ¿Quién define lo que se debe enseñar en la escuela respecto a las últimas décadas?, ¿con qué insumos cuentan los docentes para interpretar el pasado reciente que llevan al aula?, y aún más, ¿qué contenidos privilegian de los últimos tiempos y por qué? Son algunas preguntas que vale la pena formularse respecto a esta realidad y sus posibilidades de enseñanza. Los pasados traumáticos que se resisten a pasar incomodan al presente, son problemáticos para la sociedad y para la escuela que cuestiona las versiones oficiales, sobre todo cuando este pasado pone en entredicho la legitimidad misma del Estado (Carretero y Borrelli, 2010). Es decir, la enseñanza de la historia reciente, con frecuencia, atañe a la institucionalidad y a grupos poderosos ligados a ella que han estado comprometidos con hechos que violan los derechos fundamentales de personas y comunidades y que, además, han impuesto traducciones y versiones acomodadas de ello con los numerosos medios que tienen a su disposición.

En Colombia, el estudio sobre la enseñanza de la historia reciente ha sido objeto de escaso interés investigativo; las políticas educativas han sido bastantes escuetas en su presentación y en los últimos años el centro de interés del ámbito académico ha girado básicamente sobre el impacto del conflicto en zonas de confrontación (Lizarralde, 2012), la afectación a los derechos humanos y el incremento del desplazamiento (Romero, 2013), el análisis de la guerra en la subjetividad infantil y juvenil movilizada o desmovilizada (Amador, 2010; Quintero y Ramírez, 2010; Torres, 2015), así como la adaptación de estrategias didácticas para tratar la violencia política en el aula (Arias, 2016a y 2016b; Londoño y Carvajal, 2015; Quintero, 2009) y la articulación de las discusiones sobre la memorial social, la narrativa testimonial y el ámbito educativo (Herrera y Vélez, 2014; Ortega y Herrera, 2012).

Vale resaltar la acción de un grupo de profesores de la Universidad Pedagógica Nacional, que han sido pioneros en el abordaje del tema de la violencia política y su relación con la educación en Colombia. Desde inicios de la década del 2000 el grupo Educación y Cultura Política ya insinuaba este tópico en sus monográficos sobre la cultura política en Colombia y en América Latina (Herrera, Infante, Pinilla y Díaz, 2005; Herrera, Pinilla e Infante, 2001; Herrera y Díaz, 2001); de igual forma lo hacía el grupo Sujetos y Nuevas Narrativas (Rodríguez y Sánchez, 2009a y 2009b). Estos colectivos consolidaron su producción con dos monográficos de la Revista Colombiana de Educación, uno para el 2012 (AA. vv., 2012) y otro para el 2016 (AA. VV., 2016). Estas producciones recogen, por un lado, los debates nacionales en los que se destaca la importancia de los movimientos sociales y las organizaciones de las víctimas como promotoras pedagógicas de la enseñanza de la historia reciente, sobre todo por fuera de la escuela, y por otro, los esfuerzos de algunos académicos por posicionar el tema, especialmente desde los trabajos de pregrado 
y posgrado de la Universidad Pedagógica; ejercicios de sistematización de trabajo popular, así como de repertorios artísticos y culturales para explorar el tema, y propuestas de unidades didácticas para trabajar en colegios de educación básica y media. El último monográfico contiene aportes de autores de países latinoamericanos y cosechas de otros continentes para ayudar a entender la complejidad de los pasados conflictivos en la escuela.

\section{Hallazgos}

A continuación se presentan algunos hallazgos de una investigación centrada en recabar imaginarios sobre la historia reciente en un grupo de estudiantes universitarios de Licenciatura en Ciencias Sociales de una universidad pública de Bogotá. Metodológicamente, la investigación se hizo desde un enfoque cualitativo (Strauss y Corbin, 2012), pues se trabajó con las percepciones de sujetos y sus concepciones frente a una situación social particular. En consonancia con este enfoque el método privilegiado consistió en la producción de relatos de vida, entendidos como "la indagación no estructurada sobre las historias de vida tal como son relatadas por los propios sujetos" (Kornblit, 2007, p. 15).

Las técnicas de investigación usadas fueron la entrevista a profundidad, el grupo focal y la producción de relatos escritos y visuales. Para el análisis de información se aplicó el análisis de contenido (Ruiz, 2006) y se realizaron algunos cruces con lo divulgado en libros de texto de amplia circulación nacional. Dicho estudio se realizó en el 2012, en el que estuvieron vinculados 50 estudiantes de primer semestre y 21 de séptimo, 17 de ellos participaron en las entrevistas y 11 de ellos en dos grupos focales.

En el relato escrito se les solicitó a los estudiantes que se pronunciaran sobre los contenidos de las últimas décadas que privilegiarían enseñar, en caso de que ya fueran docentes en ejercicio. El acento de la instrucción "en las últimas décadas" fue deliberado y tuvo la función de dejar abierta la gama de opciones en el momento de pensar en el pasado reciente. Esta ambigua franja temporal fue la única limi- tación que se puso. No se pidieron determinados contenidos o áreas temáticas, pues la intención fue precisamente identificar los periodos, los actores, los acontecimientos y las reflexiones sobre el pasado reciente plasmados en sus escritos.

\section{Los estudiantes universitarios y}

\section{su pasado nacional reciente}

La mayoría de relatos hechos por los jóvenes acotaron hechos y sucesos de carácter político, especialmente ligados a la violencia, tales como el conflicto interno desde la segunda mitad del siglo $\mathrm{xx}$ hasta nuestros días, el Bogotazo y el narcotráfico. Los datos políticos emblemáticos enunciados fueron principalmente la Constitución de 1991, el Frente Nacional, la Regeneración y otras particularidades de la historia; curiosamente estos acontecimientos ocurrieron a fines del siglo XIX y las primeras décadas del xx. Hechos deportivos y culturales apenas si son nombrados por algunos estudiantes $\mathrm{y}$, respecto a los grupos sociales, menciones a los cambios en el papel de la mujer y de los indígenas en la sociedad nacional son marginales. Solo algunos estudiantes de séptimo semestre manifestaron el deseo de enseñar algunas habilidades propias del pensamiento histórico, como las relaciones entre pasado, presente y futuro o el contraste de fuentes. Veamos algunos fragmentos de relatos que enlazan algunos de los acontecimientos mencionados:

La historia colombiana ha estado atravesada por una serie de acontecimientos y de personajes que han cambiado el curso de nuestra historia y que nos han llevado a ser un país como el de hoy día. Un país de extremas diferencias políticas, sociales y religiosas. Podemos mirar un poco estos acontecimientos, por ejemplo, tras una serie de inconformidades sociales, además de injusticias, en Colombia surgen ciertas guerrillas guiadas cada una por ideales traídos de otros lugares, quienes buscan cambiar ese destino. A pesar de ello, estas guerrillas no pudieron consolidarse en una sola, gracias a esas mismas diferencias ideológicas; a partir de ello ha existido una guerra entre guerrilla y ejército nacional y entre las mismas guerrillas. Sin embargo, hubo una que quiso realizar cambios por 
vía política, el M-19, gracias a su desmovilización y al diálogo con el presidente de la época, Gaviria, se crea el cambio de la Constitución de 1886, para abrir paso a la Constitución del año 1991, en la cual priman los derechos humanos y fundamentales, dando así un gran paso de esa transformación y a la disolución del Movimiento 19 de abril (Andrea, primer semestre).

La historia de Colombia desde su independencia ha marcado una serie de "círculo vicioso" [sic]. En cuanto al sentido de "mis objetivos deben ser los objetivos de todos", me explico: Desde nuestra añorada independencia, la cual costó sangre y vidas nos ha faltado la capacidad para trazar los objetivos posteriores a lo que queríamos en esa época, lo que hizo que, a pesar de que se oiga contradictorio, se hizo todo y nada, surge una lucha entre centralistas y federalistas por ejercer el poder, donde, por un lado, se quería que se manejara el país desde un solo "Estado" o que cada "Estado" tuviera su representante, fue así como por la lucha entre nosotros mismos se perdió todo por lo que se había luchado. Ahora bien, en las últimas décadas ¿qué nos ha heredado nuestra antigua historia en cuanto acciones? No se ve gran diferencia, se crean movimientos revolucionarios (FARC, ELN, M-19, etc.), los cuales luchan por la igualdad social, en el caso de las FARC que se ha catalogado [como] un grupo terrorista ¿cómo ha podido llegar hasta este punto? Su creación se debe a la injusticia hacia los campesinos ya que les quitaron sus animales, su único sustento. Supongo que hay un punto donde priman los intereses individuales. (Graciela, primer semestre).

Salvo raras excepciones, los estudiantes de primer semestre aludieron a acontecimientos de 1948 en adelante. Con la muerte de Jorge Eliécer Gaitán y el subsecuente Bogotazo, parece que el inicio de la historia reciente tiene lugar con estos sucesos en la memoria de estos jóvenes. Aun los pocos que se remontaron al descubrimiento de América, o a los acontecimientos del siglo xix que tienen que ver con la independencia y la creación de los dos partidos tradicionales, lo hicieron destacando en unos y otros hechos el componente bélico y trágico de ellos. "La historia de nuestro país en las últimas décadas y prácticamente desde su independencia ha vivido una guerra", sentencia un estudiante; otro dice: "La historia de Colombia desde su independencia ha marcado una serie de 'ć́rculo vicioso"'.

El Frente Nacional, el bipartidismo, el surgimiento y la consolidación de las guerrillas, el narcotráfico, la masacre de la Unión Patriótica, el Palacio de Justicia, la Constitución de 1991 y el paramilitarismo son los fenómenos de las últimas décadas de la historia colombiana en la que la mayoría de estudiantes coinciden, aspectos que retoman con variedad de detalle y sin mayor rigor cronológico. Salvo esporádicas alusiones a las glorias del deporte nacional o a ciertas conquistas sociales, no sobresalen relatos sobre transformaciones estructurales, cambios sociales significativos o protagonismos de otros actores. La constante de la violencia atraviesa la mención de los acontecimientos, al lado de escasas pistas de análisis y pobres posibilidades de interpretación causal de esta.

Si bien el ejercicio tuvo limitaciones de tiempo y espacio y las consideraciones analíticas son parciales, la historia que dicen escoger para enseñar estos jóvenes puede ser reflejo de la historia que aprendieron en sus experiencias escolares. Puede ser muy difícil expresar en pocos párrafos qué se privilegiaría enseñar y la instrucción se pudo entender como la solicitud de referencias generales, enunciativas, sin mayor profundidad; empero, llama la atención, en algunos jóvenes, la sucesión indeterminada de acontecimientos o las explicaciones simplistas y caricaturescas de fenómenos densos como la violencia. En todo caso se dieron constantes que pueden dar luces frente al imaginario social que circula sobre la enseñanza de la historia reciente de la nación propia.

Se observó una diferencia cualitativa de los relatos de los chicos de primero frente a los de séptimo. Los de primero fueron descriptivos, enunciativos, quizás también apresurados e imprecisos y eso se entiende por su formación escolar, pero, en general, se nota que no hubo criterios claros para ordenar estos acontecimientos, para encadenarlos o para distinguirlos, así que lo que hicieron fue una lista casi con un criterio cronológico y continuista: como si cada uno fuera causante del siguiente. Por su parte, los estudiantes de séptimo semestre, probablemente con algunas de las herramientas que han adquirido 
en su formación universitaria, acudieron menos a hechos episódicos y arriesgaron reflexiones más gruesas sobre el país. A continuación la transcripción de un fragmento de los relatos de estos últimos estudiantes:

Hoy, muchachos, vamos a analizar qué ha pasado en las últimas tres décadas: en los años ochenta el país estaba sumido en un conflicto social y armado que venía de algún tiempo atrás pero que se intensificaba debido a la llegada o formación de grandes frentes del narcotráfico que controlaban ya gran parte del territorio nacional. Finalizando esta década llega la presidencia de Belisario Betancur, con el cual se inician algunos procesos de negociación con guerrillas, como el Movimiento 19 de abril, el Ejército Popular de Liberación y la guerrilla indígena del Quintín Lame, que tenía su campo de acción en el departamento del Cauca. Finalmente, se logra un proceso de paz con el M-19 y el Quintín Lame, logrando su desmovilización. Con la llegada de los noventa y tras el asesinato del candidato liberal a la presidencia Luis Carlos Galán asume la presidencia el también liberal César Gaviria. Bajo este período se logra el proceso de la Constituyente que posteriormente redactó la Constitución de 1991, reemplazando a la de 1886. Tras este mandato le siguieron el también liberal Ernesto Samper, con él [sic] que se vivieron grandes escándalos de corrupción como el denominado Proceso 8000, luego asumió Andrés Pastrana, conservador, quien inició los diálogos fallidos con las FARC en la denominada zona de distención, [sic] posteriormente asume Álvaro Uribe Vélez quien ejerce el poder durante 8 años y con quien se acentúa la crisis humanitaria del país. (Miguel, séptimo semestre).

Plantearía los hechos colombianos que para mí son los más importantes en los últimos 50 años; empezaría con el otorgamiento del voto de la mujer, no como una reivindicación propia sino como algo otorgado, la muerte del caudillo Jorge Eliécer Gaitán con sus implicaciones a nivel político y social. La dictadura de Rojas Pinilla, el proceso 8000 de Samper Pizano, la zona de distensión dada por Andrés Pastrana, el período presidencial de Uribe Vélez, y la presidencia de Santos; todo esto para analizar las implicaciones políticas, sociales y económicas del país, y cómo las políticas lideradas por cada uno de estos representantes ha[n] dado paso a las configuraciones actuales. También ahondaría en temas como Estado, gobierno, ciudadanía, ética, moral, espacio-tiempo; para redefinir los hechos materiales y teorizarlos. Por último, entraría a la parte crítica y conclusiva de la enseñanza que nos permita generar actitudes propositivas de transformación, reformador. (Lida, séptimo semestre)

En conjunto, en los estudiantes de séptimo semestre resalta la evocación de acontecimientos violentos que en buena parte coinciden con los relatos de primero, con algo más de protagonismo de los jóvenes mismos, pero, finalmente, con la tragedia nacional como telón de fondo. ¿Qué significa esta violencia que tanto aparece? ¿Qué implicaciones tiene para la escuela y la enseñanza de las ciencias sociales referida al tiempo reciente que los jóvenes entiendan la violencia, implícita o explícitamente, como marca recurrente de la historia de las últimas décadas? Y más aún ¿por qué estos jóvenes asumen que la violencia y la guerra es la constante de los hechos por enseñar en las aulas?

\section{La violencia como marca de}

\section{la historia colombiana}

Algunos teóricos de las ciencias sociales han considerado la violencia como la marca que ha permitido a muchos colombianos sentirse parte de un territorio común, de una historia compartida, de una tragedia vinculante (Patiño, 2005). La violencia en el país no es una abstracción, pues ha sido la forma como se ha conformado el Estado, se han configurado las regiones y ha sido el mecanismo usual de articulación de los poderes locales, regionales y nacionales (Bolívar, 2003). En Colombia existe un imaginario de la violencia, con su macabro correlato de realidad, con su rédito político y económico difundido por los medios de comunicación, en los que se mezcla la violencia política, la social, la intrafamiliar en una sola argamasa que no establece diferenciaciones y que de alguna manera, en medio de su espectacularización, ha logrado saturar a quien la padece y a quien no.

Los relatos de estos estudiantes universitarios expresan una opinión común instalada en la cultura 
política del colombiano; tras la sentencia "los colombianos somos violentos" se camuflan agresiones de toda índole, padecidas por sujetos aislados y sectores sociales. Así, se invisibilizan causalidades, se acallan responsabilidades y se esquivan los determinantes de la estructura social que han potenciado fuertemente este fenómeno. Si todos somos víctimas y victimarios, no hay lugar para los responsables. Si la violencia viene del aire que respiramos, no hay espacio para transformar contextos y avizorar salidas posibles. Si el atropello a los otros está inscrito en nuestros genes, no es posible identificar una instancia para diferenciar niveles, jerarquías, protagonismos, ni dolientes. El estigma de la violencia, vuelta síndrome de identificación nacional, se convierte así en mecanismo expedito de etiquetamiento y en simplista clave interpretativa de toda la dinámica sociopolítica de la historia nacional. "Se sabe desde antiguo que los dominados pueden llegar a interiorizar la estigmatización de que son objeto, reconociéndose como efectivamente inferiores, inhábiles e ignorantes" (Giménez, 2005, p. 94).

Salvo algunas excepciones, la sombra nefasta de la violencia y de la guerra, matizada por el protagonismo de líderes políticos, presidentes y uno que otro artista es el relato que cuentan la mayoría de estudiantes participantes cuando se les convoca a enseñar la historia reciente. Hay situaciones concretas, hechos, acontecimientos complejos violentos que articulan la historia nacional y que marcan una especie de sinsalida para estos jóvenes.

Estos escolares reproducen un imaginario social que proviene de muchas fuentes y que, parece, la educación escolar, recrea hasta volverlo parte del registro escolar (Kriger, 2011). Para encontrar contraste, se comparó con algunas tablas de contenido de libros de texto de editoriales reconocidas en el país que reflejan aspectos de lo que se pretende introducir en el aula en grado noveno, dado que se ha vuelto norma, en el currículo colombiano, que este nivel se dedica a profundizar en la historia de la nación.

Si bien los libros de texto y las estrategias didácticas que proponen las editoriales han de ser confrontadas con la forma como se trabaja en el aula, ellos permiten desentrañar las intenciones a las que sirven en relación con la transmisión de ideas, valores e imaginarios (Ossenbach, 2006). En la tabla de contenido de tres textos se pudo observar una dispersión de hechos, cuya constante es el énfasis en la historia política y militar del siglo xx. La violencia aparece en nodos específicos, pero no es central en cuanto a la articulación de las temáticas.

Pese al contenido enciclopédico que impera en la escuela, particularmente en la asignatura de ciencias sociales, en la que los escolares asisten a gran cantidad de temas propios de la disciplina, llama la atención que muchos jóvenes, en la distancia, solo retomen aquellos relacionados con las temáticas del conflicto y la violencia. Este tema, a diferencia de otros, en cuanto registro escolar, se interseca con lo que sucede fuera de la escuela, transversaliza los medios de comunicación y se toca con las noticias diarias de radio y televisión. La violencia, en sus múltiples modalidades, remite a la cotidianidad de una nación que, a falta de otros elementos para reconocerse, ha encontrado en ella el modo de rastrear la imagen de sí misma. Sin embargo, algunos testimonios, pocos, dieron cuenta de miradas ricas y complejas, de énfasis en procesos, de análisis globales y preguntas por campos sociales, o de vínculos con el arte y la literatura, más que datos puntuales.

Las respuestas de la mayoría de jóvenes, cuyo énfasis narrativo recae en víctimas y victimarios, de algún modo coinciden con un estudio hecho en el país (Larreamendy, 2002) con niños y jóvenes acerca de los orígenes del movimiento guerrillero, en el que los resultados arrojan grandes generalizaciones, ausencia de detalle histórico y fuerte esquematismo que reside en el uso de parejas de actores que reducen la diversidad del problema a antagonismos dicotómicos que pretenden capturar la esencia del conflicto. Dice el autor al presentar las conclusiones: "Los políticos versus el pueblo, los corruptos versus los honestos, los ricos versus los pobres. La mayoría de explicaciones se ordenó alrededor de este tipo de oposiciones, sin dar cabida a un abanico más enriquecido de actores" (Larreamendy, 2002, p. 216). 
Por otro lado, el sensacionalismo de la violencia garantiza rating. Su manejo en telenovelas y películas ha sido el recurso reiterado que libretistas y directores han seleccionado para generar audiencia y para vender al exterior las producciones nacionales. Sin negar la contundencia de su imponente realidad, los espectadores colombianos aprenden a perseguir el pasado con ese filtro, a verificar sus huellas en la historia y a remembrar mayoritariamente sus secuelas. La violencia ha llegado a ser un discurso legitimado y legitimador (Pedraza, 2012). Sin reconciliaciones, sin exorcismos comunitarios, sin duelos oficiales, sin juicios definitivos ${ }^{3} y$ con las heridas abiertas, los colombianos sacamos la violencia de la agenda pública la mayor parte del tiempo, de manera que la política estatal transcurre eludiendo este drama, mientras el torrente de la violencia, palpitante en el espectro socialy cultural, y presente en la mayor parte de la nación campea poderosamente con eventuales erupciones en la superficie de la sociedad y, sobre todo, operando como discurso narrativo de la imagen del nosotros nacional.

Por ello, aunque el conflicto armado en el país ha cobrado millares de víctimas, representa para muchos conciudadanos un asunto ajeno a su entorno y a sus intereses. La violencia de la desaparición forzada, la violencia sobre el líder sindical perseguido, la violencia del desplazamiento forzado, la del campesino amenazado y despojado de su tierra, la de la violencia sexual y tantas otras suelen quedar marginadas de la esfera pública, se viven en medio de profundas y dolorosas soledades. En suma, la cotidianización de la violencia, por un lado, y la ruralidad y el anonimato en el plano nacional de la inmensa mayoría de víctimas, por el otro, han dado lugar a una actitud si no de pasividad, sí de indiferencia, alimentada, además, por una cómoda percepción de estabilidad política y económica. (Grupo Memoria Histórica, 2013, p. 14).

A este mismo respecto, dice Carlos Perea que "la violencia cumple con la función simbólica de arrastrar en sus mallas de sentido la vida colectiva, en particular

3 El Grupo Memoria Histórica de la Universidad Nacional habla de 220.000 muertos en los últimos 50 años de conflicto (Grupo Memoria Histórica, 2013). en determinados periodos" (2009, p. 20). Tal función, reificada a fuerza de hechos traumáticos, se transmuta, mediante dolorosos ejercicios de reiteración, en clave interpretativa de la supuesta idiosincrasia de lo nacional. Quizá gracias a que la violencia ha podido instalarse en la cultura ha sido tan exitosa su raigambre, a la vez que han sido tan amorfas y dispersas sus tramitaciones. Como sociedad, Colombia no ha procesado este drama por muchos motivos.

Uno de ellos, no menor, tiene que ver con la vigencia y permanencia del conflicto que cobra tantas vidas en el territorio nacional. Tener a la fecha uno de los mayores números de desplazados del mundo, sindicalistas asesinados, defensores de derechos humanos amenazados y uno de los conflictos armados más viejos del continente son datos de primer orden en el momento de caracterizar y justificar un imaginario sobre la violencia.

Desterrada de la agenda pública, pero acogida y deformada por otras instancias, la violencia ha logrado instalarse en las memorias nacionales, ha perdido complejidad y ha simplificado sus características en las versiones escolares que se nutren básicamente del sentido común, de libros de texto y de películas y telenovelas. Se pierde la trama histórica, se diluyen responsabilidades o se concentran en las personas de seres espectacularizados. Tal versión oscila entre una tragedia de la que no es posible escapar y cuentos episódicos y fragmentados regentados por hombres magnánimos o extremadamente viles. La sociedad de la que emergieron estos sujetos desaparece, los contextos apenas si son mencionados, las realidades locales y regionales, las redes internacionales se tornan invisibles. Las estructuras económicas y políticas salen ilesas. El poder cumple con su cometido de hacer ver que, en el pasado como en el presente, la violencia tiene que ver con causas fortuitas y azarosas.

Parece, además evidente, que el trámite que la enseñanza escolar ha hecho de este fenómeno no ha posibilitado su comprensión histórica ya que su dramatismo opera como un currículo no formal que se resiste a dejar de ser central en los imaginarios escolares y cuya impronta oficial también perdura en las versiones mediáticas. Para el Grupo Cyberia, 
... la manera como ha sido abordado este tema fue y sigue siendo orientada desde la mirada apologética [... lo que no ha permitido visualizar "otras memorias" alternativas a la memoria oficial. Así mismo, en el momento en que las ciencias sociales abordan actualmente el fenómeno de la primera violencia, se han visto reforzadas las vías de la rememoración ${ }^{4}$, activando los ritos del duelo y del recuerdo de hechos trágicos de esta fecha, erigiendo así personajes o caudillos y falsas representaciones simbólicas que desde la historia oficial se han plasmado en la cultura y en lenguaje de las sociedad [sic] (2009, p. 254).

En efecto, como se observa en las tablas de contenido de algunos libros de texto colombianos de noveno grado, la violencia y sus ramificaciones ocupan un lugar en los contenidos referidos a la historia del país, su abordaje es cronológico y su expresión visible son los hechos emblemáticos propios de lo político y lo militar. No aparecen títulos que indiquen abordajes complejos, miradas de larga duración o lecturas confrontadas sobre los mismos fenómenos o acontecimientos históricos objeto de estudio. Mucho menos se pueden leer aspectos de una historia social y la cultural del país, que son marginales en estos importantes instrumentos didácticos. Si bien esto no es reflejo necesario ni mecánico de lo que sucede en las escuelas y en las aulas, puede ofrecer algunas pistas para entender el enfocado repertorio de datos alusivos a las guerras $\mathrm{y}$ a las secuelas que reportan los estudiantes cuando son invitados a tejer la historia que quisieran enseñar.

Esta situación realza la sentencia que Federico Lorenz (2006) expusiera para el caso de la educación en Argentina y que valdría para el caso que nos ocupa:

Si [bien] es cierto que la enseñanza y la apropiación [del pasado reciente] implican una cierta ruptura

4 Para el Grupo Cyberia existe una diferencia radical entre rememorar y conmemorar. La rememoración, propia de los discursos oficiales, acude a los dolores del pasado sin establecer vínculos con el presente, sin marcar la existencia de los sujetos que rememoran; por su parte, la conmemoración trasciende la remembranza de héroes y fechas, identifica memorias en pugna y promueve permanentemente relaciones y compromisos con el presente. con ese pasado que se recibe, también lo es que, si éste es transmitido en tonos absolutos, sagrados $-y$, por ende, intangibles-, dicho proceso de ruptura es imposible. El resultado, lo opuesto a lo buscado, es entonces una cristalización de imágenes acerca del pasado, una ritualización que puede transformar en irrelevante un valor, vital para una sociedad. Entonces, no solo se banaliza el pasado, sino que se contribuye a fijar a los actores sociales en un miedo y un dolor que se dice querer procesar (pp. 282-283).

De alguna manera, se entiende que los estudiantes de primer semestre enfaticen en esta mirada que, obnubilada por la violencia, desconoce otras aristas de la realidad nacional reciente; pero de los estudiantes de séptimo semestre, exceptuando dos o tres, se esperaría que contaran con herramientas conceptuales que le imprimieran a sus relatos otros abordajes, gracias a su formación y trayectoria.

El discurso de la violencia parece privilegiarse en la escuela y se alcanza a evidenciar en los relatos de los estudiantes de la Licenciatura en Ciencias Sociales que participaron de la presente investigación. En cuanto a los temas de interés para enseñar, este discurso da cuenta de los densos vínculos que existen entre esta institución y la sociedad, pero también de la debilidad de los currículos explícitos y de la fuerza de un imaginario social sobre la importancia de la violencia como sello de lo que supuestamente somos como colombianos. Además, trasluce cierta angustia por un deber de la memoria (Carnovale y Larramendy, 2010) que idealiza las víctimas, a la vez que las vuelve anónimas e interpreta el pasado como una guerra de malos y buenos; víctimas y victimarios. Se da así una lectura categórica y maniquea de la historia, que invisibiliza los asuntos ideológicos, políticos y sociales imprescindibles para comprenderla. Sobre este asunto, Carnovale y Larramendy (2010) afirman:

Es plausible sostener que este escenario encuentra una razón de peso en la ausencia de saberes y de consensos básicos en las distintas tramas que conforman el sistema educativo acerca de los contenidos específicos para enseñar. Sin embargo, debe seña- 
larse que el problema de la transmisión del pasado reciente excede en mucho la escuela e involucra a los más variados espacios políticos, institucionales, culturales, entre otros (p. 245).

A tono con este planteamiento, es posible afirmar que los problemas surgidos de tratar la historia reciente en la escuela hablan más de los conflictos no resueltos de la sociedad que de la escuela misma, aunque ello no es obstáculo para pensar desde allí criterios, enfoques y propuestas didácticas para contrarrestar en algo las lecturas simplistas que campean al respecto.

\section{Conclusiones}

En síntesis, respecto a los imaginarios y concepciones sobre enseñanza de la historia reciente en la escuela se encontró una diferencia entre los estudiantes de primero y séptimo semestre. Los de primero dieron cuenta de relatos episódicos y fragmentarios centrados en grandes personajes, acontecimientos emblemáticos y secuenciales. Los de séptimo, algo más complejos en sus versiones, enunciaron sucesos en orden cronológico y, al igual que sus compañeros de primer semestre, mayoritariamente de orden político y militar. Unos y otros entendieron la consigna "historia de las últimas décadas" de manera nominativa y ambigua, y se centraron en pocos aspectos del siglo xix y fundamentalmente de la segunda mitad del $x x$.

Pese a contadas singularidades que expresaron la posibilidad de narrar una historia de Colombia basada en procesos y campos tensionales o recursos literarios, la gran mayoría privilegiaría enseñar asuntos relacionados con la política y sobre todo con la violencia. Parece así que la violencia y sus secuelas fungen como tropo de la enseñanza de la historia de las últimas décadas, según los relatos de los jóvenes universitarios auscultados. Sobre ello se matizó la importancia de entender la conflictiva realidad nacional, la dificultad para tramitar socialmente los traumas y los dolores producto de la muerte, el desplazamiento y la amenaza de miles y miles de personas, sumada a la incapacidad de la escuela para generar comprensión histórica sobre este fenómeno. Es decir, parece que la escuela no ha logrado ofrecer las herramientas necesarias para salir de cierto "lugar común" de la historia nacional, instalado gracias al imaginario social que naturaliza la violencia sin ofrecer pistas para entender, procesar y superar el fenómeno.

Entonces, ¿qué historia nacional enseñar? Aunque excede los alcances del presente estudio, se puede sugerir que es pertinente una mirada más enfocada en los procesos que en los acontecimientos, una apuesta por aproximaciones a categorías explicativas generales que articulen fenómenos locales, nacionales e internacionales. Trascender la mera enunciación descriptiva de hechos traumáticos para recaer sobre sus condiciones de posibilidad, lo que supera la coyuntura o la anécdota de las fechas. Esto significa inscribir los acontecimientos en lecturas de mediana y larga duración (Elias, 1987), invitar a los estudiantes a identificar los diferentes actores involucrados, sus versiones de los hechos y sembrar más preguntas que verdades sobre tramas variopintas que dejan opacidades, hilos sueltos y detalles sobre los que permanentemente emergen nuevos datos ${ }^{5}$.

Además, la incorporación en la escuela de los contenidos propios del pasado reciente excede con creces el debate sobre la recuperación o no de la historia en el currículo (Arias, 2015 a y b), pues cristaliza aspectos de orden ético y político que implican en tipo de sociedad en curso y aquella por construir. A este nivel le cabe la responsabilidad a los docentes de aula contrarrestar las limitaciones de las políticas educativas al respecto, así como la articulación con otras iniciativas extraescolares que procuran disputar las versiones legítimas sobre lo que hechos sido como nación y lo que podríamos llegar a ser.

5 Para la fecha en que se escribe este texto aparece nueva información sobre la Junta Militar de la dictadura argentina, 30 años después; se trata de archivos de actas originales de las reuniones entre 1976 y 1983 encontrados en el sótano de un edificio, en los cuales aparecen seguimientos y nombres de empresas comprometidas con el régimen. Por otro lado, en Colombia, aparecen nuevas pruebas que inculpan a otros altos militares por los desaparecidos del Palacio de Justicia en 1985 (información disponible en: http://noticiasunolaredindependiente. com/2013/11/04/noticias/foto-sargento-garzon/ (10-11-13). 


\section{Referencias}

AA. vv. (2012). Monográfico: Historia, memoria y formación: violencia sociopolítica y conflicto armado. Revista Colombiana de Educación, 62.

AA. vv. (2016). Monográfico: Educación, subjetividades y memoria en procesos de transición política. Revista Colombiana de Educación, 71.

Amador, J. (2010). El intersticio de la víctima-victimario: un análisis de los procesos de subjetivación de cuatro niños, niñas y jóvenes desvinculados de grupos armados en Colombia. Revista Universitas Humanistica, 69, 163-184.

Arias, D. (2005). Enseñanza y aprendizaje de las ciencias sociales. Una propuesta didáctica. Bogotá: Cooperativa Editorial Magisterio.

Arias, D . (2015a). La enseñanza de la historia reciente y la formación moral. Dilemas de un vínculo imprescindible. Folios, 42, 29-41.

Arias, D. (2015b). La enseñanza de las ciencias sociales en Colombia: lugar de las disciplinas y disputa por la hegemonía de un saber. Revista de Estudios Sociales, 52, 134-146.

Arias, D. (2016a). Enseñanza sobre el conflicto y la violencia política, aportes desde la formación humanista y la imaginación narrativa. En: D. Arias y F. Molano (eds.), Escuela y formación humanista. Miradas desde la investigación educativa (pp. 175-191). Bogotá: Universidad de La Salle.

Arias, D. (2016b). La memoria y la enseñanza de la violencia política desde estrategias audiovisuales. Revista Colombiana de Educación, 71, 253-278.

Bolívar, İ. (2003). Violencia política y formación del Estado. Ensayo historiográfico sobre la dinámica regional de la Violencia de los cincuenta en Colombia. Bogotá: Universidad de los Andes.

Carnovale, V., y Larramendy, A. (2010). Enseñar la historia reciente en la escuela: problemas y aportes para su abordaje. En I. Siede, Ciencias sociales en la escuela. Criterios y propuestas para la enseñanza (pp. 239-267). Buenos Aires: Aique.

Comisión Histórica del Conflicto y sus Víctimas (2015). Contribución al entendimiento del conflicto armado en Colombia. S.c.

Cyberia, Grupo (2009). Memorias de la primera violencia en la enseñanza de las ciencias sociales. En A. Jiménez y F. Guerra (comps.), Las luchas por la memoria (pp. 239-262). Bogotá: Universidad Distrital Francisco José de Caldas.

De Amézola, G. (2008). Esquizohistoria. La historia que se enseña en la escuela, la que preocupa a los historia- dores y una renovación posible de la historia escolar. Buenos Aires: Libros del Zorzal.

Elias, N. (1987). El proceso de civilización. Investigaciones sociogenéticas y psicogenéticas. México: Fondo de Cultura Económica.

Funes, P. (2006). Salvar la nación. Intelectuales, cultura y política en los años veinte latinoamericanos. Buenos Aires: Prometeo.

Giménez, G. (2005). Teoría y análisis de la cultura (vol. 1). México: Conaculta.

Goodson, I. (1991). La construcción social del currículum. Posibilidades y ámbitos de investigación de la historia del currículum. Revista de Educación, 295, 7-37.

Grupo Memoria Histórica (2013). ¡Basta Ya! Colombia: memorias de guerra y dignidad. Bogotá: Imprenta Nacional.

Herrera, M. y Diaz, C. (comps.) (2001). Educación y cultura política: una mirada multidisciplinaria. Bogotá: Universidad Pedagógica Nacional.

Herrera, M., Infante, R., Pinilla, A. y Díaz, C. (2005). La construcción de la cultura política en Colombia. Proyectos hegemónicos y resistencias culturales. Bogotá: Universidad Pedagógica Nacional.

Herrera, M. y Ortega, P. (2012). Memorias de la violencia política y formación ético-política de jóvenes y maestros en Colombia. Revista Colombiana de Educación, 62, 88-115.

Herrera, M., Pinilla, A. e Infante, R. (2001). Conflicto educativo y cultura política en Colombia. Nómadas, $15,40-49$.

Herrera, M. y Vélez, G. (2014). Formación política en el tiempo presente: ecologías violentas y pedagogía de la memoria. Nómadas, 41, 149-161.

Higuera, D. (2012). La escuela ante la transmisión del pasado reciente argentino: sentidos comunes, dilemas de la representación y los desafíos del presente. Buenos Aires: Libros Libres, Flacso.

Kriger, M. (2011). La enseñanza de la historia reciente como herramienta clave de la educación política. Persona y Sociedad, 3, 29-52.

Kornblit, A. L. (2007). Historias y relatos de vida: una herramienta clave en metodologías cualitativas. En A. L. Kornblit, Metodologías cualitativas en ciencias sociales. Modelos y procedimientos de análisis (pp. 15-33). Buenos Aires: Biblos.

Larreamendy, J. (2002). Pensamiento histórico, educación y conflicto armado. En M. Bello y S. Ruiz, Conflicto armado, niñez y juventud. Una perspectiva psicosocial (pp. 209-231). Bogotá: Universidad Nacional de Colombia, Fundación Dos Mundos. 
Levín, F. (2007). El pasado reciente en la escuela, entre los dilemas de la historia y la memoria. En G. Schujman e I. Siede, Ciudadanía para armar. Aportes para la formación ética y política (pp. 157-178). Buenos Aires: Aique.

Lizarralde, M. (2012). La escuela y la guerra, las memorias entre el miedo y el silencio. Praxis Pedagógica, 13, 90-103.

Londoño, J. y Carvajal, J. (2015). Pedagogías para la memoria histórica: reflexiones y consideraciones para un proceso de innovación en el aula. Ciudad Paz-ando, 8, 124-141.

Lorenz, F. (2006). El pasado reciente en la Argentina: las difíciles relaciones entre transmisión, educación y memoria. En M. Carretero, A. Rosa y M. González, Enseñanza de la historia y memoria colectiva (pp. 277295). Buenos Aires: Paidós.

Ortega, P. y Herrera, M. (2012). Memorias de la violencia política y formación ético-política de jóvenes y maestros en Colombia. Revista Colombiana de Educación, 62, 89-115.

Ossenbach, G. (2006). Prólogo. En C. Kaufmann, Dictadura y educación. Los textos escolares en la historia argentina reciente (pp. 7-12). Buenos Aires: Miño y Dávila.

Patiño, C. (2005). El mito de la nación violenta. Los intelectuales, la violencia y el discurso de la guerra en la construcción de la identidad nacional colombiana. En F. Colom, Relatos de Nación. La construcción de las identidades nacionales (pp. 1095-1114). Madrid: Iberoamericana.

Pedraza, Z. (2012). La disposición del gobierno de la vida: acercamiento a la práctica biopolítica en Colombia. Revista Estudios Sociales, 43, 94-107.

Perea, C. (2009). Cultura política y violencia en Colombia. Porque la sangre es espíritu. Bogotá: La Carreta.

Quintero, M. (2009). Enseñanza de la historia del conflicto armado en Colombia: fundamentos para la construcción de propuestas para su enseñanza en el ámbito universitario. Revista Latinoamericana de Estudios Educativos, 5, 205-230.

Quintero, M. y Ramírez, J. (2010). Narraciones, memorias y ciudadanía. Desplazamiento Forzado. Bogotá: Universidad Distrital Francisco José de Caldas.

Rodríguez, S. y Sánchez, M. (2009a). Problemáticas de la enseñanza de la historia reciente en Colombia: trabajar con la memoria en un país en guerra. Reseñas de Enseñanza de la Historia, 7, 15-66.

Rodríguez, S. y Sánchez, M. (2009b). Narrativa, memoria y enseñanza del conflicto armado colombiano: propuesta para superar las políticas de olvido e impunidad. En A. Serna y D. Gómez (comps.), El papel de la memoria en los laberintos de la verdad, la justicia y la reparación: memorias del seminario internacional (pp. 203-229). Bogotá: Universidad Distrital Francisco José de Caldas.

Romero, F. (2013). Conflicto armado, escuela, derechos humanos y DIH en Colombia. Revista Análisis Político, $77,57-84$.

Rubio, G. (2013). Memoria, política y pedagogía. Los caminos hacia la enseñanza del pasado reciente en Chile. Santiago: LOM.

Ruiz, A. (2006). Texto, testimonio y metatexto. El análisis de contenido en la investigación en educación. En A. Torres y A. Jiménez, La práctica investigativa en ciencias sociales (pp. 43-59). Bogotá: Universidad Pedagógica Nacional.

Strauss, A. y Corbin, J. (2012). Bases de la investigación cualitativa. Técnicas y procedimientos para desarrollar la teoría fundamentada. Medellín: Universidad de Antioquia.

Torres, E. (2015). Narratividad y tiempo: niños y niñas desvinculados del conflicto armado colombiano. En D. Calderón (ed.), Lenguaje, cultura e investigación: problemas emergentes en educación (pp. 59-82). Bogotá: Universidad Distrital Francisco José de Caldas. 